\title{
Температурная зависимость ширины запрещенной зоны монокристаллов $\mathrm{MnAgln_{7 }} \mathbf{S}_{12}$
}

\author{
(C) И.В. Боднарь ${ }^{1}$, Б.Т. Чан ${ }^{1}$, В.Н. Павловский ${ }^{2}$, И.Е. Свитенков ${ }^{2}$, Г.П. Яблонский ${ }^{2}$ \\ ${ }^{1}$ Белорусский государственный университет инорорматики и радиоэлектроники, \\ 220013 Минск, Беларусь \\ ${ }^{2}$ Институт фризики Национальной академии наук Беларуси, \\ 220072 Минск, Беларусь \\ E-mail: chemzav@bsuir.by
}

Поступила в Редакцию 23 июля 2019 г.

В окончательной редакции 29 июля 2019 г.

Принята к публикации 29 июля 2019 г.

\begin{abstract}
Направленной кристаллизацией расплава выращены монокристаллы $\mathrm{MnAgIn} \mathrm{S}_{12}$ диаметром 16 и длиной $\sim 40$ мм, определены их состав и структура. Показано, что выращенный материал кристаллизуется в кубической структуре шпинели. По спектрам пропускания в области края фундаментального поглощения в интервале температур $10-320 \mathrm{~K}$ определена ширина запрещенной зоны $E_{g}$ монокристаллов и построена ее температурная зависимость. Полученная зависимость имеет вид, характерный для большинства полупроводниковых материалов: с понижением температуры $E_{g}$ возрастает. Проведен расчет, и показано, что расчетные и экспериментальные величины согласуются между собой.
\end{abstract}

Ключевые слова: монокристаллы, кубическая структура шпинели, спектры пропускания, ширина запрещенной зоны.

DOI: 10.21883/FTP.2019.12.48614.9221

\section{1. Введение}

Тройное соединение $\mathrm{MnIn}_{2} \mathrm{~S}_{4}$ относится к группе магнитных полупроводников, $\operatorname{AgIn}_{5} \mathrm{~S}_{8}$ - к группе дефектных полупроводников с концентрацией вакансий в катионной подрешетке $\sim 25 \%$. Указанные соединения являются перспективными материалами для создания на их основе лазеров, фотопреобразователей солнечного излучения, электрооптических модуляторов и других функциональных устройств [1-6].

В настоящей работе представлены результаты выращивания монокристаллов $\mathrm{MnAgIn}_{7} \mathrm{~S}_{12}$, исследования их кристаллической структуры и спектров пропускания в интервале температур $T=10-320 \mathrm{~K}$.

\section{2. Методика эксперимента}

Выращивание монокристаллов $\mathrm{MnAgIn}{ }_{7} \mathrm{~S}_{12}$ проводили в два этапа. На первом этапе проводили синтез кристаллов двухтемпературным методом. В этом методе ампулу помещают в двухзонную горизонтальную печь, температуры зон которой можно регулировать независимо друг от друга. Перед загрузкой исходных компонентов в ампулы они проходили предварительную химико-термическую обработку.

Элементарные компоненты (серебро, индий, марганец) чистотой $>99.99 \%$, взятые в соотношениях, соответствующих составу соединения или твердого раствора, загружали в кварцевую лодочку, которую располагали в одном конце кварцевой ампулы. В противоположном ее конце находилась сера, взятая с избытком относительно стехиометрии, необходимым для создания давления ее паров над расплавом $\sim 2.0$ атм. После откачки ампулы до остаточного давления $\sim 10^{-3}$ Па ее отпаивали от вакуумной системы и располагали в горизонтальной двухзонной печи таким образом, чтобы лодочка с металлическими компонентами находилась в „горячей“ зоне печи, а сера - в „холодной“ зоне. Общее давление в ампуле определяется температурой ,холодной“ зоны, которую можно регулировать таким образом, что давление в ампуле не будет превышать допустимое.

Температуру „горячей“ зоны устанавливали $\sim 1400 \mathrm{~K}$. Температуру „холодной“ зоны повышали со скоростью $\sim 100 \mathrm{~K} /$ ч до $\sim 700 \mathrm{~K}$ и выдерживали в течение 2 ч (для протекания реакции между металлическими компонентами и парами серы). Для более полного протекания этой реакции температуру с такой же скоростью повышали до $950 \mathrm{~K}$ с повторной выдержкой в течение 1 ч. По истечении указанного времени проводили направленную кристаллизацию расплава путем понижения температуры в зоне, где находились металлические компоненты, до $800 \mathrm{~K}$ и печь отключали от сети. Полученные кристаллы использовались для выращивания монокристаллов методом Бриджмена.

Синтезированные слитки перегружали в двойные кварцевые ампулы, из которых внутренняя ампула заканчивалась цилиндрическим капилляром, обеспечивающим формирование монокристаллической затравки. После вакуумирования ампул к наружной ампуле снизу приваривали кварцевый стержень, служивший держателем.

Выращивание монокристаллов проводили в вертикальной однозонной печи с заданным температурным градиентом. Температуру в печи повышали со скоро- 
стью $\sim 250 \mathrm{~K} /$ ч до $\sim 1400 \mathrm{~K}$ и выдерживали при этой температуре 2 ч, после чего проводили направленную кристаллизацию расплава, понижая температуру печи со скоростью $\sim 2 \mathrm{~K} /$ ч до полного затвердевания расплава. Для гомогенизации полученных монокристаллов их отжигали при $1000 \mathrm{~K}$ в течение $\sim 400$ ч. Выращенные в таких условиях монокристаллы имели диаметр $\sim 16$ и длину $\sim 40$ мм, были однородными и гомогенными, что установлено методами микрорентгеноспектрального и рентгеновского анализов.

Состав выращенных монокристаллов $\operatorname{MnAgIn}_{7} \mathrm{~S}_{12}$ определяли с помощью микрозондового рентгеноспектрального анализа на установке „Сатеса-SX 100“. Относительная погрешность определения компонентов составляла $\pm 5 \%$.

Структуру полученных монокристаллов $\operatorname{MnAgIn}{ }_{7} \mathrm{~S}_{12}$ определяли рентгеновским методом. Угловые положения линий дифракционного спектра записывали на рентгеновском аппарате ДРОН-3М в $\mathrm{Cu} K_{\alpha}$-излучении с графитовым монохроматором. Образцы для измерений готовили путем измельчения кристаллов и последующей их запрессовкой в специальном держателе. Для снятия механических напряжений, возникающих при растирании кристаллов, проводили их отжиг в вакууме при температуре $700 \mathrm{~K}$ в течение 2 ч.

Спектры пропускания в области температур $T=10-320 \mathrm{~K}$ измеряли на установке, состоящей из гелиевого рефрижератора замкнутого цикла, монохроматора, кремниевой ПЗС-линейки, галогеновой лампы в качестве источника излучения и персонального компьютера. Для проведения измерений из выращенных монокристаллов вырезали плоскопараллельные пластинки перпендикулярно оси роста, которые механически шлифовали и полировали с двух сторон. Для снятия нарушенного слоя, образовавшегося при механической обработке монокристаллов, непосредственно перед измерениями спектров образцы подвергали обработке в травителе состава $\left[\mathrm{Br}_{2}\right]:\left[\mathrm{C}_{2} \mathrm{H}_{5} \mathrm{OH}\right]=1: 3$. Толщина образцов составляла $\sim 20$ мкм.

\section{3. Экспериментальные результаты}

Результаты микрозондового рентгеноспектрального анализа показали, что содержание элементов в выращенных монокристаллах $([\mathrm{Mn}]:[\mathrm{Ag}]:[\mathrm{In}]:[\mathrm{S}]=$ $=4.91: 4.66: 33.24: 57.19)$ хорошо согласуется с заданным составом в исходной шихте $([\mathrm{Mn}]:[\mathrm{Ag}]:[\mathrm{In}]:[\mathrm{S}]=$ $=4.76: 4.76: 33.34: 57.14)$.

Дифрактограмма, углы отражения $(2 \theta)$, межплоскостные расстояния $(d)$, относительные интенсивности рефлексов $\left(I / I_{0}\right)$, индексы Миллера $(h k l)$ для монокристаллов MnAgIn $\mathrm{S}_{12}$. представлены на рис. 1 и в таблице. Дирактограмма содержит систему линий, характерную для кубической структуры шпинели. Параметр элементарной ячейки, рассчитанный методом наименьших квадратов, равен $a=(10.779 \pm 0.005) \AA$.

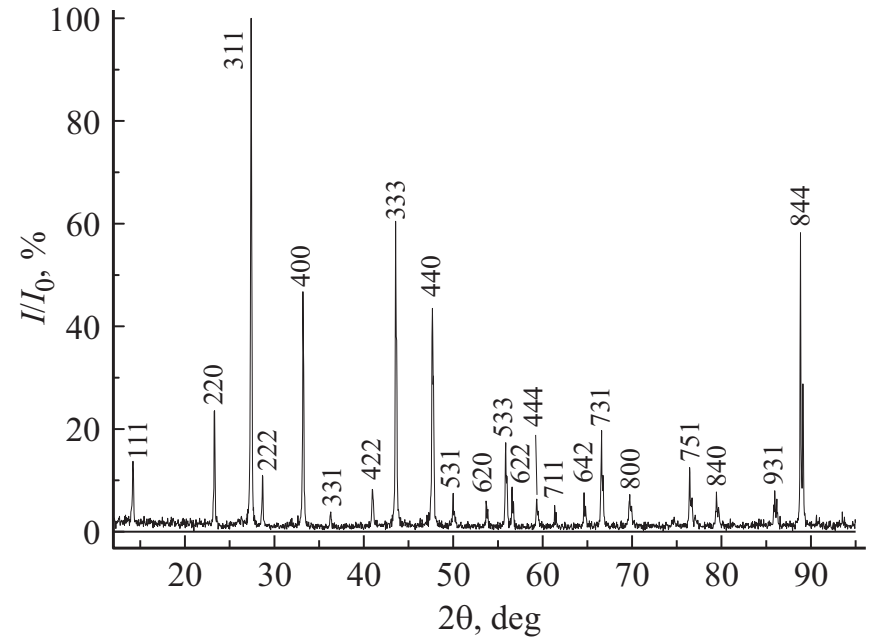

Pис. 1. Дифрактограмма монокристаллов $\mathrm{MnAgIn}_{7} \mathrm{~S}_{12}$.

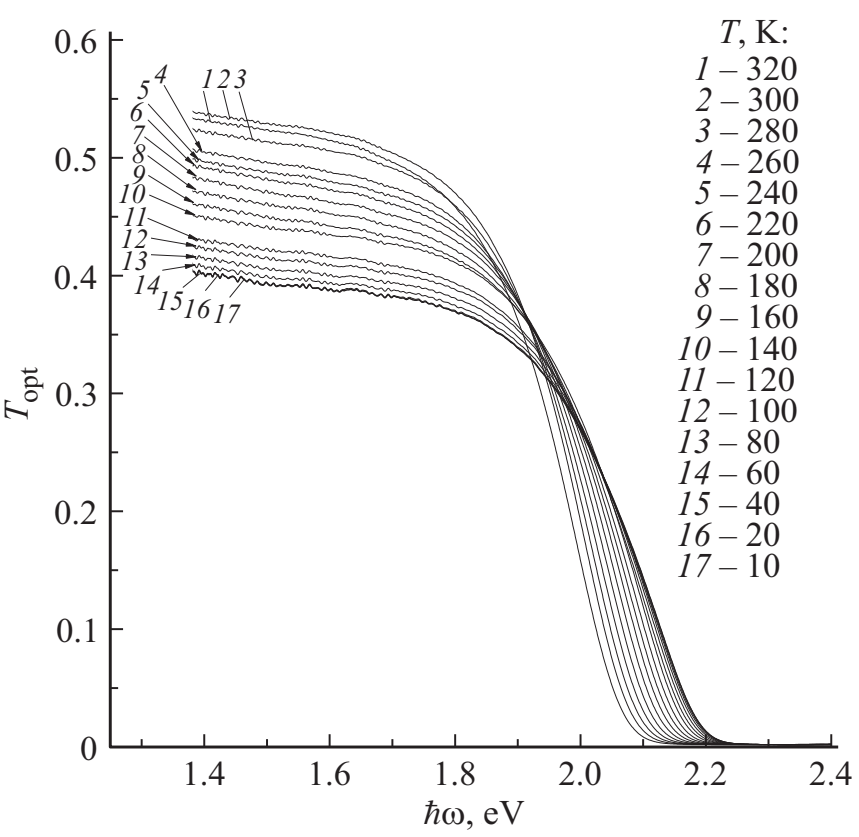

Рис. 2. Спектры пропускания монокристаллов $\mathrm{MnAgIn}_{7} \mathrm{~S}_{12}$ в интервале температур $10-320 \mathrm{~K}$.

Спектры пропускания монокристаллов $\mathrm{MnAgIn}_{7} \mathrm{~S}_{12}$ в области края собственного поглощения в интервале температур $T=10-320 \mathrm{~K}$ представлены на рис. 2. Видно, что с понижением температуры спектры смещаются в коротковолновую область.

Из зарегистрированных спектров пропускания $\left(T_{\text {opt }}\right)$ рассчитывали коэффициент поглощения $(\alpha)$ по формуле, учитывающей многократное внутреннее отражение в плоскопараллельном образце [7-9]:

$$
\alpha=\frac{1}{d_{0}} \ln \left\{\frac{(1-R)^{2}}{2 T_{\mathrm{opt}}}+\sqrt{\left[\frac{(1-R)^{2}}{2 T_{\mathrm{opt}}}\right]^{2}+R^{2}}\right\},
$$

где $d-$ толщина образца, $R-$ коэффициент отражения. 
Результаты рентгеновского анализа монокристаллов $\operatorname{MnAgIn}_{7} \mathrm{~S}_{12}$

\begin{tabular}{c|c|c|l|l|c|l}
\hline \multirow{2}{*}{$\begin{array}{c}\text { № } \\
\text { рефлекса }\end{array}$} & \multicolumn{2}{|c|}{$2 \theta$, град } & \multicolumn{2}{|c|}{$d, \AA$} & \multirow{2}{*}{$\begin{array}{c}\text { I/I } \\
\%\end{array}$} & \multirow{2}{*}{$h k l$} \\
\cline { 2 - 5 } & эксп. & расч. & эксп. & расч. & & \\
\hline 1 & 14.22 & 14.22 & 6.22 & 6.22 & 14 & 111 \\
2 & 23.32 & 23.32 & 3.8112 & 3.8112 & 24 & 220 \\
3 & 27.42 & 27.42 & 3.2499 & 3.2499 & 100 & 311 \\
4 & 28.67 & 28.66 & 3.1112 & 3.1114 & 11 & 222 \\
5 & 33.22 & 33.21 & 2.6945 & 2.6946 & 42 & 400 \\
6 & 36.30 & 36.29 & 2.4727 & 2.4732 & 4 & 331 \\
7 & 40.97 & 40.98 & 2.2009 & 2.2004 & 8.5 & 422 \\
8 & 43.58 & 43.59 & 2.0759 & 2.0745 & 55 & 333 \\
9 & 47.68 & 47.68 & 1.9057 & 1.9057 & 43 & 440 \\
10 & 50.00 & 50.01 & 1.8225 & 1.822 & 6.5 & 531 \\
11 & 53.73 & 53.73 & 1.6647 & 1.6647 & 6 & 620 \\
12 & 55.86 & 55.88 & 1.6444 & 1.6439 & 17 & 533 \\
13 & 56.57 & 56.58 & 1.6255 & 1.6252 & 9 & 622 \\
14 & 59.34 & 59.34 & 1.5559 & 1.5559 & 6.5 & 444 \\
15 & 61.37 & 61.36 & 1.5094 & 1.5096 & 5 & 711 \\
16 & 64.65 & 64.65 & 1.4405 & 1.4405 & 7.2 & 642 \\
17 & 66.59 & 66.57 & 1.4031 & 1.4034 & 18 & 731 \\
18 & 69.74 & 69.73 & 1.3473 & 1.3474 & 7 & 800 \\
19 & 76.46 & 76.46 & 1.2447 & 1.2447 & 12 & 751 \\
20 & 79.46 & 79.45 & 1.2050 & 1.2052 & 7.2 & 840 \\
21 & 85.96 & 85.94 & 1.1298 & 1.1299 & 7.3 & 931 \\
22 & 88.87 & 88.87 & 1.1002 & 1.1002 & 52 & 844
\end{tabular}

Примечание. Приводятся расчетные (расч.) и экспериментальные (эксп.) данные.

Ширину запрещенной зоны монокристаллов $\mathrm{MnAgIn}_{7} \mathrm{~S}_{12}$ определяли экстраполяцией прямолинейного участка зависимости $(\alpha \hbar \omega)^{2}$ от энергии фотона $(\hbar \omega)$ до пересечения с осью абсцисс (рис. 3). Полученные нами значения ширины запрещенной зоны для

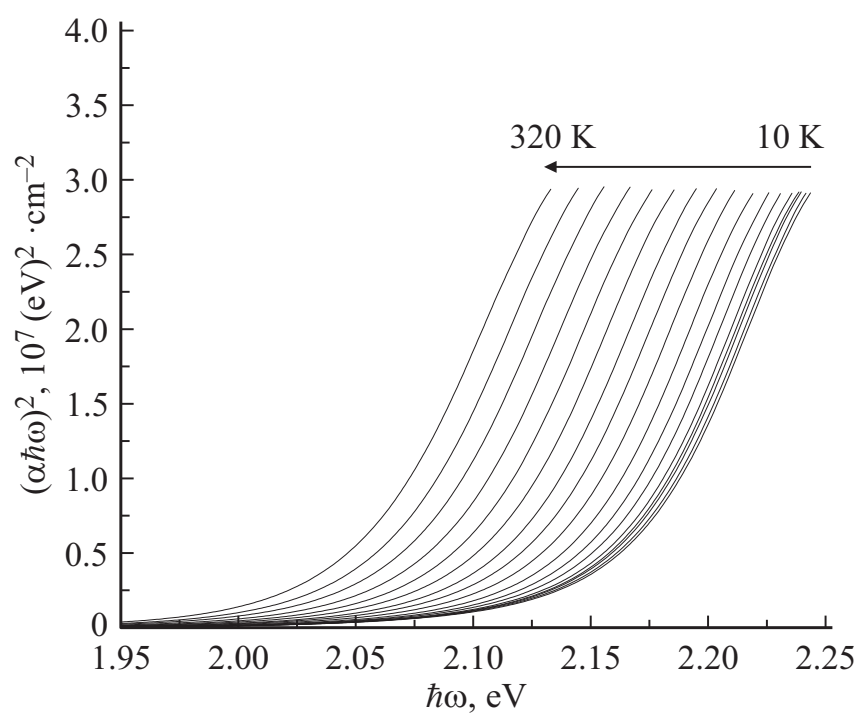

Рис. 3. Спектральные зависимости $(\alpha \hbar \omega)^{2}$ от $(\hbar \omega)$ для монокристаллов $\mathrm{MnAgIn}_{7} \mathrm{~S}_{12}$ при температурах 10, 20, 40, 60, $80,100,120,140,160,180,200,220,240,260,280,300,320 \mathrm{~K}$.

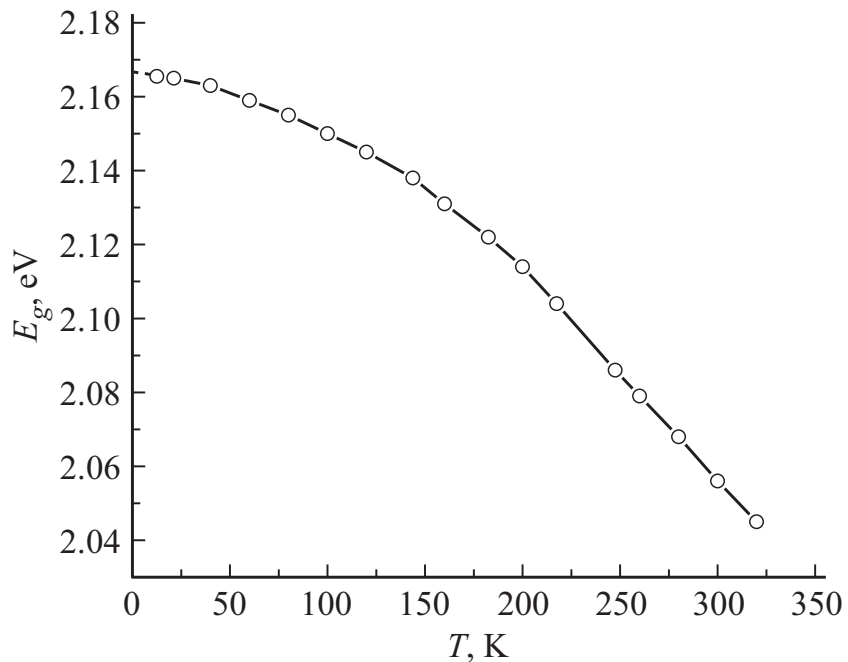

Рис. 4. Температурная зависимость ширины запрещенной зоны $E_{g}(T)$ для монокристаллов $\mathrm{MnAgIn}_{7} \mathrm{~S}_{12}$.

монокристаллов $\mathrm{MnAgIn}_{7} \mathrm{~S}_{12}$ равны $E_{g}=2.060,2.154$ и 2.165 эВ при 300,80 и $10 \mathrm{~K}$ соответственно.

На рис. 4 представлена температурная зависимость ширины запрещенной зоны $E_{g}(T)$ монокристалла $\mathrm{MnAgIn}_{7} \mathrm{~S}_{12}$, полученная на основе экспериментальных данных по измерениям коэффициента пропускания в интервале температур 10-320 K точки. Видно, что указанная зависимость имеет вид, характерный для большинства полупроводниковых материалов, с понижением температуры $E_{g}$ возрастает [10-12].

Для описания температурной зависимость ширины запрещенной зоны было использовано следующее выражение [13]:

$$
E_{g}(T)=E_{g}(0) \frac{\chi \Theta}{2}\left(\sqrt[4]{1+\frac{\pi^{2}}{6}\left(\frac{2 T}{\Theta}\right)^{2}+\left(\frac{2 T}{\Theta}\right)^{4}-1}\right)
$$

где $E_{g}(0)$ - ширина запрещенной зоны при $T=0 \mathrm{~K}$, $\chi$ - параметр, определяющий тангенс угла наклона касательной к кривой $E_{g}(T), \chi=-d E(T) /\left.d T\right|_{T \rightarrow \infty}, \Theta-$ эффективная фононная температура (предполагается, что она меньше температуры Дебая $\left.\Theta_{\mathrm{D}}: \Theta \approx(3 / 4) \Theta_{\mathrm{D}}^{\alpha}\right)$.

Величину $\chi$ определяли путем нахождения зависимости, наилучшим образом удовлетворяющей экспериментальным данным $E_{g}(T)$ в интервале температур $10-320 \mathrm{~K}$. Расчетная зависимость $E_{g}(T)$ по соотношению (2) представлена на рис. 4 в виде сплошной линии. Видно, что экспериментальные результаты хорошо согласуются с расчетными величинами.

\section{4. Заключение}

Методом Бриджмена выращены монокристаллы $\operatorname{MnAgIn} \mathrm{S}_{12}$, определены их состав и структура. Показано, что выращенные монокристаллы кристаллизуются 
в структуре кубической шпинели. По спектрам пропускания в интервале температур 10-320 K определена ширина запрещенной зоны монокристаллов $\mathrm{MnAgIn}_{7} \mathrm{~S}_{12}$ и построена ее температурная зависимость. Показано, что с понижением температуры ширина запрещенной зоны возрастает.

\section{Финансирование работы}

Работа выполнена при поддержке Белорусского республиканского фонда фундаментальных исследований (проектФ16-028).

\section{Конфликт интересов}

Авторы заявляют об отсутствии конфликта интересов.

\section{Список литературы}

[1] И.В. Боднарь, В.Ю. Рудь, Ю.В. Рудь. ФТП, 43, 1549 (2009).

[2] В.Ю. Рудь, Ю.В. Рудь, М.А. Осипова, И.В. Боднарь. ФТП, 44, 48 (2010).

[3] Н.Н. Нифтиев, О.Б. Тагиев. ФТП, 38, 164 (2004).

[4] И.В. Боднарь, Е.А. Кудрицкая, И.К. Полушина, В.Ю. Рудь, Ю.В. Рудь. ФТП, 32, 1043 (1998).

[5] И.В. Боднарь, В.Ф. Гременок, В.Ю. Рудь, Ю.В. Рудь. ФТП, 33, 805 (1999).

[6] I.V. Bodnar, I.A. Victorov, V.M. Dabranski, M.A. Osipova. Phys. Status Solidi C, 6, 1130 (2009).

[7] Ю.И. Уханов. Оптические свойства полупроводников (М., Наука, 1977).

[8] С.И. Рембеза. Методы измерения основных параметров полупроводников (Воронеж, Изд-во ВГУ, 1989).

[9] Р. Уиллардсон. Оптические свойства полупроводников (М., Мир, 1970).

[10] И.В. Боднарь. ФТП, 49, 596 (2015).

[11] S. Levchenko, D. Dumcenco, Y.P. Wang, Y.S. Huang, C.H. Ho, E. Arushanov, V. Tezlevan, K.K. Tiong. Optical Mater., 34, 1362 (2012).

[12] I.V. Bodnar, I.T. Bodnar, V.F. Gremenok, A.M. Kovalchuk, M. Leon. J. Cryst. Growth, 293, 324 (2006)

[13] R. Passler. J. Appl. Phys., 90, 3956 (2001).

Редактор Л.В. Шаронова

\section{Temperature dependence of $M n A g I n_{7} S_{12}$ single crystals energe gap}

\author{
I.V. Bodnar ${ }^{1}$, B.T. Chan ${ }^{1}$, V.N. Pavlovskii ${ }^{2}$, \\ I.E. Svitenkov ${ }^{2}$, G.P. Yablonskii ${ }^{2}$ \\ ${ }^{1}$ Belarussian State University of Informatics \\ and Radioelectonics, \\ 220013 Minsk, Belarus \\ ${ }^{2}$ Institute of Physics, \\ National Academy of Sciences of Belarus, \\ 220072 Minsk, Belarus
}

Abstract The $\operatorname{MnAgIn}_{7} \mathrm{~S}_{12}$ single crystals with the diameter of 16 and the length of $\sim 40 \mathrm{~mm}$ were grown by directional crystallization of the melt, their composition and structure were determined. It was shown that the grown single crystals crystallized in the cubic structure of spinel. From the transmittance spectra in the region of the fundamental absorption edge in the temperature range $10-320 \mathrm{~K}$, the band gap $E_{g}$ of these single crystals was determined and its temperature dependence was constructed. It has been established that this dependence has the form characteristic of most semiconductor materials: with decreasing temperature $E_{g}$ increases. The calculation of the specified temperature dependence was performed. It is shown that the calculated and experimental values are consistent with each other. 